\title{
A CASE REPORT OF INCISIONAL HERNIA THROUGH A 5MM SUPRAPUBIC PORT SITE FOLLOWING LAPAROSCOPIC APPENDICECTOMY
}

\author{
K. Ravichandran¹, M. Senthil Velan², M. Karthik³, Imran Thariq Ajmal'4, K. Prasanna Venkatesan ${ }^{5}$
}

\section{HOW TO CITE THIS ARTICLE:}

K. Ravichandran, M. Senthil Velan, M. Karthik, Imran Thariq Ajmal, K. Prasanna Venkatesan. "A Case Report of Incisional Hernia through a 5mm Suprapubic Port Site following Laparoscopic Appendicectomy". Journal of Evolution of Medical and Dental Sciences 2014; Vol. 3, Issue 73, December 25; Page: 15448-15452,

DOI: $10.14260 /$ jemds/2014/4082

ABSTRACT: INTRODUCTION: Less than $10 \mathrm{~mm}$ port-site herniation is a rare complication after laparoscopic surgery. We report a case of complicated herniation through the 5 -mm suprapubic trocar port site. CASE REPORT: A 58-year old obese male was admitted due to intestinal obstruction. He has undergone the laparoscopic appendicectomy 1 year ago. On examination, abdomen was bloated and roughly $10 \mathrm{~cm}$ size mass was palpable on the suprapubic area. Plane radiogram of the abdomen showed signs of intestinal obstruction. Since conservative treatment was ineffective, the patient was operated on. The laparotomy revealed a protrusion of a part of right large intestine and greater omentum into the subcutaneous space through the abdominal wall defect. There was a dilatation of intestines proximally incarcerated colon. It was released and a part of omentum was resected. The peritoneum and fascia-muscular defect was closed by interrupted vicryl sutures. CONCLUSION: Acute herniation through a $5 \mathrm{~mm}$ size most lateral trocar port site is a rare complication of laparoscopic surgery requiring prompt differential diagnosis.

KEYWORDS: Bowel obstruction, appendicectomy, Laparoscopy, Lateral $5 \mathrm{~mm}$ port, Port-site hernia.

INTRODUCTION: Laparoscopic surgery has quickly developed, becoming in some cases the gold standard procedure as the preferred mode of access to the peritoneal cavity.[1] Despite the minimal invasiveness, some laparoscopic procedures-related complications can be directly attributed to abdominal access with laparoscopic trocars. The postoperative port-site hernia formation, which is defined as the development of a hernia at the canula insertion site, is one of them. ${ }^{[2]}$

The trocar site hernia is a rare but potentially dangerous complication of laparoscopic surgery ranging from early small omental herniations to delayed hernia formation with or without bowel entrapment.[1,2] The prevalence of herniation followed by laparoscopic surgery is reported to be $0.0002 \%-6 \% .{ }^{[2-7]}$ In contrast, the true prevalence of such complications may be higher because some patients have no symptoms and do not return to the surgeon for follow - up.[5]

Almost all trocar site hernias have been found in sites greater than or equal to $10 \mathrm{~mm}$ with only few cases reported of $5 \mathrm{~mm}$ site herniation.[6-8] It is important to emphasize that 640 postoperative hernia repairs were performed in our institution during 2004-2011. Seventy eight (14\%) of them were related with previous laparoscopic interventions. Specifically, 75 (96\%) patients underwent laparoscopic cholecystectomy. We report a case of the patient who developed late complicated incisional hernia at the suprapubic $5 \mathrm{~mm}$ trocar insertion site that was produced during the elective laparoscopic treatment of acute appendicitis. This is still a rare event.

CASE REPORT: A 58-year-old obese male patient with BMI 36 was admitted to the acute care hospital due to the $72 \mathrm{~h}$ duration intermittent abdominal pain, nausea, vomiting, and abdomen enlargement with inability to pass stool or flatus, as well. It was known that the patient had 


\section{CASE REPORT}

undergone an elective laparoscopic appendicectomy a year ago. The major symptoms were revealed on examination: distended abdomen, and a tender $10 \mathrm{~cm}$ size palpable mass in the suprapubic region near the $5 \mathrm{~mm}$ port-site scar. There were no signs of peritonitis. All hematological and biochemical parameters were within normal limits. Plane radiogram of the abdomen showed signs of obstruction of small and large intestines, multiple air-fluid levels with gas in the colon. Ultrasound revealed dilated fluid filled loops of bowel with no free fluid in abdominal cavity. Conservative treatment aimed to gastrointestinal decompression by nasogastric tube as well as enemas, and crystalloid fluid installations was started.

However, it was ineffective within $16 \mathrm{~h}$. Furthermore, plain radiograms revealed signs of worsening intestinal obstruction. The patient was taken for middle laparotomy with diagnosis of complete intestinal obstruction. Surgery revealed enlarged small intestine, caecum and ascending colon. It was specified that a cause of the intestinal obstruction was the herniation of initial part of transverse colon with a part of greater omentum through $6 \mathrm{~cm}$ diameter fascial-muscular defect. The large intestine was reposted back without causing damage. It was viable. Roughly, $500 \mathrm{~g}$ of inflamed greater omentum was removed. The fascial-muscular defect was closed with interrupted Vycril 2/0 sutures. The patient recovered well after the procedure.

DISCUSSION: Following issues regarding this case can be disputable: first, what is the place of $5 \mathrm{~mm}$ port site hernia within suggested classifications regarding post-trocar hernia; second, what might be factors which had causal relationship to the development of the port-site hernia; third, what might be additional options for diagnostics and best management of this disease; lastly, whether the $5 \mathrm{~mm}$ port-site hernia is preventable or not.

The classification of trocar port-site hernias was suggested in 2004.[7] They were classified into three types. The early onset trocar port hernia type was defined as having dehiscence of fascia and peritoneum within 2 weeks, most commonly with small bowel obstruction. When hernia occurs after 2 weeks and has dehiscence of fascial plane with a sac consisting of peritoneum, it is classified as a late onset type port-site hernia. Only a small part of late onset hernias present with intestinal obstruction. The third category includes special types of hernia which have dehiscence of the whole abdominal wall.[2,7,9] We would refer the case to the category of special types trocar $5 \mathrm{~mm}$ port-site hernia with the late progressive dehiscence of peritoneum, muscular and fascial planes resulting herniation and incarceration of right colon and omentum. Nevertheless, it also might be referred partly to the late onset $5 \mathrm{~mm}$ trocar port-site hernia because there was confirmed dehiscence of fascial plain with a sac consisting of peritoneum.

Many factors causing intra-abdominal hernias after laparoscopic surgery have been emphasized. Such as the number of trocars used and their diameters, the duration of the procedure (the longer it takes, the higher risk is), the aponeurotic defects in trocar place (incomplete closure of fascia), the insertion technique, the method of withdrawing the trocar, midline trocars, stretching the port site for organ retrieval, the effect of a partial vacuum while port withdrawal, obesity, poor nutrition, and operation site infection. ${ }^{[1,2,4,7-9]}$ Laparoscopic procedures that require multiple trocars are associated with a higher frequency of hernias. It is known that using $10 \mathrm{~mm}$ and larger trocars results in increased risk of hernias.[1] Trocar made aponeurotic defects smaller than $10 \mathrm{~mm}$, like in our case, rarely can cause herniation and bowel obstruction. In an experimental study of wounds relative to the type of trocar, it was found that a non-bladed trocar created smaller peritoneal port 


\section{CASE REPORT}

site wounds than a conventional pyramidal tip.[9] Some authors have also reported a lower prevalence of hernias with the use of a paramedian incision and non-bladed trocars which have a conical tip. ${ }^{[2]}$ Nevertheless, port site created by a non-bladed trocar requires fascial closure.[10]

There is just one obvious risk factor for development of lateral $5 \mathrm{~mm}$ port site hernia in our patient. It is obesity. It is also important to note that there were no unusual protocolized surgery features during a laparoscopic cholecystectomy performed a year ago. In contrast, a careful protocoling of every surgical step which includes formation even $5 \mathrm{~mm}$ trocar port site and, later, possible manipulations through this port should be a concern of great importance. Unknown risk factors could be involved in a process of herniation through $5 \mathrm{~mm}$ size trocar port in our patient.

Clinical courses of port-site hernia are varied and depend on the cause of intestinal obstruction, degree of intestinal entry to the abdominal wall defect and some constitutional features such as a presence of obesity. A plain radiogram is a useful tool for early diagnostics of the existence or non-existence of the bowel obstruction. However, they have limited value in diagnosing complicated lateral port-site hernia. ${ }^{[9]}$ Abdominal CT-scan should be employed as a definitive urgent diagnostic method as it can differentiate colon neoplasm or adhesions from complicated port-site hernia.[9] Regarding our patient, doctors on call did not suspect acute herniation in indicated abdominal region. The patient was treated conservatively even $16 \mathrm{~h}$ from admission due to high probability of obstruction related with right colon malignancy. Only urgent explorative laparotomy revealed a cause of large bowel obstruction.

Theoretically, the management of most of these hernias includes widening of the trocar site, reduction of the hernia and further surgeries based on the bowel viability. ${ }^{[7,8]}$ We fully followed these requirements. In our view, the key point at this stage of discussion is the following: even such rare entity as postoperative hernia at the previous site of introduction of the smallest laparoscopic trocar in most lateral side of the abdomen can be responsible for acute intestinal obstruction and, therefore, must be kept in mind during diagnostic differentiation because time of surgery is a most crucial thing in the management of incarcerated hernias.

Finally, there are some measures suggested to prevent trocar port-site hernia.[7,10-12] To the best of our knowledge they are as follows: the use, whenever it possible, of trocars of smaller diameter, avoiding extreme manipulation of trocars, introducing trocars with a Z-incision technique, closing fascial defect, direct vision deflation air and removing of trocars. Many authors have recommended the deflation of pneumo-peritoneum prior to port removal so that omentum and intestines would not be drawn into the fascial defect.[1,7,13] The trocar must be removed under direct visualization, and the wound should be digitally explored, assuring that no bowel has been entrapped. Adequate closure of the fascia for wounds larger than $10 \mathrm{~mm}$ is necessary. In general, the closure of the fascia in a wound of $10 \mathrm{~mm}$ or smaller is questioned.[12]

However, some surgeons recommend closing $5 \mathrm{~mm}$ port in patients who are older than 60 years of age with a BMI above 25, whose laparoscopic surgery duration is longer than 90 min and after extensive trocar manipulation.[5,14] The peritoneum should be incorporated into the fascial closure to obliterate the preperitoneal space, thereby preventing herniation. Some authors mentioned that closure should be done under direct vision, and it should incorporate all layers of the abdominal wall to eliminate the peritoneal defect.[12] Some surgeons recommended the use of a fascial closure device, a spinal cord needle, a suture carrier, a 2-mm trocar, an Endoclose suture device, or a Deschamps needle to close the fascia and the peritoneum together.[10,12] 
We use the deschamps needle for closure of larger than $10 \mathrm{~mm}$ trocars and leave smaller unclosed. All that means that surgeon performing laparoscopic operation must follow recommendations mentioned. If not, every specific step of surgery should be protocolized and justified in order to give a suitable chance for correct and prompt clinical audit and review.

CONCLUSIONS: Acute herniation through a $5 \mathrm{~mm}$ size most suprapubic trocar port site is a very rare complication of laparoscopic surgery. It should always be included in the differential diagnosis of bowel obstruction when a patient has undergone any laparoscopic procedure. Additional steps for clarifying risk factors for this type and site trocar port-site hernia should be undertaken.

\section{REFERENCES:}

1. Teixeira F, Yoo JH, Junior AJ. Incisional hernia at the insertion site of the laparoscopic trocar: Case report and the review of the literature. Rev Hosp Clin Fac Med S Paulo. 2003; 58: 219-22. [PubMed]

2. Rao P, Ghosh K, Sudhan L. Port site hernia: A rare complication of laparoscopy. Medical Journal Armed Forces India. 2008; 64: 87-188.

3. Cadeddu NO, Schlachta CM, Mamazza J, Sechadri PA, Poulin EC. Trocar site hernias after laparoscopic procedures. Can J Surg. 2002; 45:9-10. [PMC free article] [PubMed]

4. Thapar A, Kianifard B, Pyper R, Woods W. $5 \mathrm{~mm}$ port site hernia causing small bowel obstruction. Gynecol Surg. 2008; 7: 713.

5. Reardon PR, Preciado A, Scarborough T, Metthews B, Marti JL. Hernia at $5 \mathrm{~mm}$ port site presenting as early postoperative small bowel obstruction. J Laparoendosc Adv Surg Tech A. 1999; 9: 523-5. [PubMed]

6. Bergeman JL, Hibbert ML, Harkins GD, Narvaez J, Asato A. Omental herniation through a 3-mm umbilical trocar site: Unmasking a hidden umbilical hernia. J Laparoendosc Adv Surg Tech A. 2001; 11: 171-3. [PubMed]

7. Tonouchiet H, Ohmori Y, Kobayashi M, Kusunoki M. Trocar site hernia. Arch Surg. 2004; 139: 1248-56. [PubMed]

8. O’Donoghue G, Mann B. Laparoscopic trocar site herniae. BMJ Case Reports. 2009 [PMC free article] [PubMed]

9. Lee JH, Kim W. Strangulated small bowel hernia through the port site: A case report. World J Gastroenterol. 2008; 14 (44): 6881-6883. [PMC free article] [PubMed]

10. Lorenzo ND, Coscarella G, Lirosi F, Gaspari A. Port-site closure: A new problem, an old device. J Soc Laparoendosc Surg. 2002; 6: 181-3.

11. Liu CD, McFadden DW. Laparoscopic port sites do not require fascial closure when non bladed trocars are used. Am Surg. 2000; 66: 853-4. [PubMed]

12. Rastogi V, Dy V. Simple technique for proper approximation and closure of peritoneal and rectus sheath defects at port site after laparoscopic surgery. J Laparoendosc Adv Surg Tech A. 2001; 11: 13-6. [PubMed]

13. Trehan AK. Richter's hernia following operative laparoscopy. Gynaecol Endosc. 1996; 5: 353-4.

14. Uslu YU, Erkek AB, Cakmak A, Kepenekci I, Sozener U, Kocaay FA, et al. Trocar site hernia after laparoscopic cholecystectomy. J Laparoendosc Adv Surg Tech A. 2007; 17: 600-3. [PubMed] 


\section{CASE REPORT}

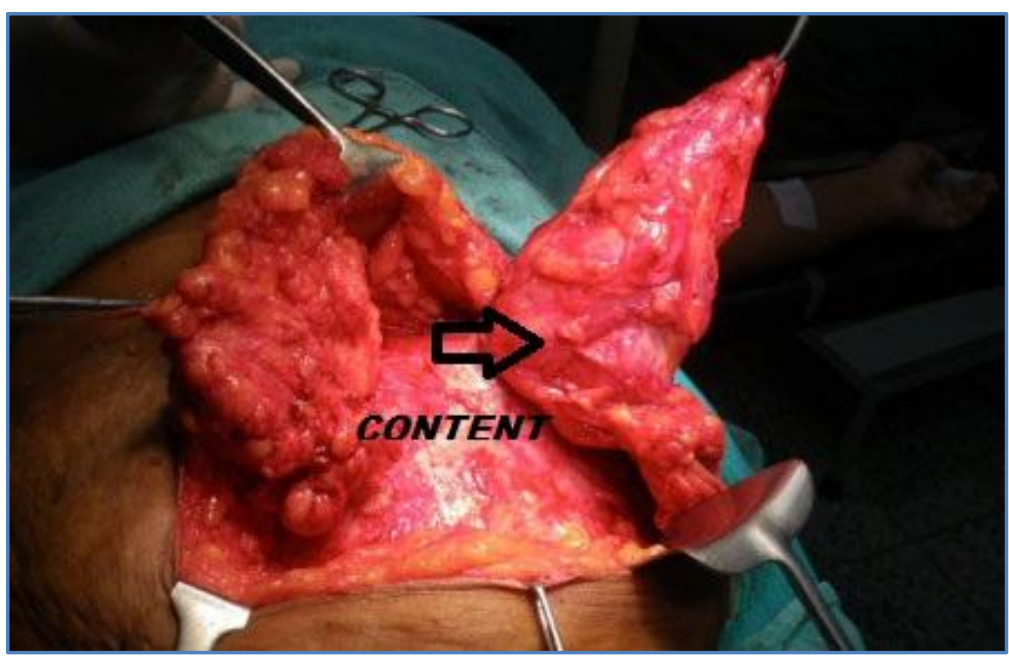

\section{Fig. 1}

\section{AUTHORS:}

1. K. Ravichandran

2. M. Senthil Velan

3. M. Karthik

4. Imran Thariq Ajmal

5. K. Prasanna Venkatesan

\section{PARTICULARS OF CONTRIBUTORS:}

1. Assistant Professor, Department of General Surgery, Rajah Muthaiah Medical College.

2. Professor, Department of General Surgery, Rajah Muthaiah Medical College.

3. Assistant Professor, Department of General Surgery, Rajah Muthaiah Medical College.

4. Assistant Professor, Department of General Surgery, Rajah Muthaiah Medical College.
5. Final Year Post Graduate, Department of General Surgery, Rajah Muthaiah Medical College.

\section{NAME ADDRESS EMAIL ID OF THE CORRESPONDING AUTHOR:}

Dr. K. Ravichandran,

No. 21, Venugopal Street,

Chidambaram-608001,

Email: drkravichandranyadav@gmail.com

Date of Submission: 03/10/2014.

Date of Peer Review: 06/10/2014.

Date of Acceptance: 17/12/2014.

Date of Publishing: 24/12/2014. 